\title{
The Diagnosis of CAD in Women: Addressing the Unmet Need-A Report from the National Expert Roundtable Meeting
}

\author{
Janice L. Clarke, RN, ${ }^{1}$ Joseph L. Ladapo, MD, PhD, ${ }^{2}$ Mark Monane, MD, MS, FACP, ${ }^{3}$ \\ Alexandra Lansky, MD, FESC, FACC, ${ }^{4}$ Alexandria Skoufalos, EdD, and David B. Nash, MD, MBA
}

\begin{abstract}
A multistakeholder panel comprising experts in the fields of clinical cardiology, medical technology innovation, women's health research and policy analysis, personalized medicine, payers (including self-insured employers), patient advocacy, and health economics was convened at the Heart House in Washington, DC. The following points emerged as key concepts: (1) Diagnostic challenges in the evaluation of women with symptoms suggestive of obstructive coronary artery disease (CAD) result from: $(a)$ presentation with atypical symptoms and lower pretest probability of disease compared to men, $(b)$ fatty tissue and breast tissue attenuation on cardiac imaging leading to false positive findings, and $(c)$ the presence of microvascular CAD. (2) Diagnostic challenges lead to both over-testing of low-risk women and under-testing of high-risk women. (3) Efforts should be directed toward increasing clinician, clinical professional society, and consumer awareness and understanding of sex-specific differences between men and women in the pathophysiology of CAD. (4) Multiple health care stakeholders should be made aware of new advances in genomic approaches to address the challenges of diagnosing obstructive CAD; specifically, the Corus CAD gene expression test, which was shown to have high sensitivity and negative predictive value in a recent clinical trial. As such, it has promise as a tool to help clinicians to rule out obstructive CAD as a cause of a patient's symptoms. (Population Health Management 2015;18:86-92)
\end{abstract}

\section{Introduction}

M ORE THAN A DECADE AGO, an Institute of Medicine report titled Exploring the Biological Contributions to Human Health: Does Sex Matter? concluded that:

- Sex should be considered in the design and analysis of studies in all health-related research.

- Study of sex differences must go beyond observational research to better understand mechanisms and therapies related to sex differences.

- Barriers to the advancement of knowledge about sex differences in health and illness must be eliminated. ${ }^{1}$

In 2010, a consortium of scientific investigators and health care professional thought leaders convened at the Heart Institute at Cedars-Sinai Medical Center in Los Angeles, California, to discuss sex differences in cardiovascular disease and their implications for diagnosis and therapies. In their report on the proceedings, Bairey Merz and colleagues ${ }^{2}$ noted that, despite a substantial amount of observational data documenting the existence of sex differences in cardiovascular disease, there was a significant knowledge gap regarding basic mechanisms and relevant pathophysiology to explain these differences. Recommendations called for an evolution in research and a transition from observational studies to more scientifically robust investigation into sexspecific mechanisms. The rationale was that, with improved understanding of these mechanisms, targeted diagnostic tools and therapies could be developed to improve outcomes for women.

Although some progress has been made toward addressing the issues raised by the 2010 consortium, coronary artery disease (CAD) and its clinical aftereffects (ie, myocardial infarction [MI], heart failure) continue to be the world's leading cause of morbidity and mortality in both women and men. ${ }^{3}$ Because there are sex-specific differences

\footnotetext{
${ }^{1}$ Jefferson School of Population Health, Philadelphia, Pennsylvania.

${ }^{2}$ Section on Value and Effectiveness, School of Population Health, New York, New York.

${ }^{3}$ CardioDx, Inc., Redwood City, California.

${ }^{4}$ Interventional Cardiovascular Research, Yale University School of Medicine, New Haven, Connecticut.
} 
in CAD manifestation and also because symptoms tend to be nonspecific and highly variable in women, diagnosing CAD and ischemic heart disease remains a challenge for clinicians when evaluating female patients. ${ }^{4}$ For these reasons, clinicians and patients seeking a definitive diagnosis have relied on progressive testing starting with noninvasive imaging for patients presumed to be at low-to-intermediate risk and culminating in invasive coronary angiography (ICA) for patients thought to be at higher risk. This pattern of assessment has led to overuse of these diagnostic tests and unnecessary exposure to procedural risks and complications in the majority of female patients who do not have obstructive CAD. ${ }^{5,6}$

The American Heart Association (AHA) consensus statement also recommends noninvasive testing in women with a high pretest likelihood of obstructive CAD. The high rate of false negative results that has been observed in this subset of women underscores the need for a more reliable rule-out test. ${ }^{7}$ Results from recent clinical trials evaluating a new sex-specific blood test, using gene expression, indicate that the test can assist clinicians in ruling out obstructive CAD with a $96 \%$ negative predictive value (NPV) and $88 \%$ sensitivity in a combined population of men and women. ${ }^{8}$
In February 2014, a multistakeholder panel comprising experts in the fields of clinical cardiology, medical technology innovation, women's health research and policy analysis, personalized medicine, employer group and other health insurance, patient advocacy, and health economics was convened at the Heart House in Washington, DC, by the Jefferson School of Population Health and the Society for Women's Health Research, with sponsorship by CardioDx, Inc. to: (1) review the evidence pertaining to sex differences in anatomy/physiology and symptoms of obstructive CAD; (2) discuss the appropriate use, risks, and benefits of noninvasive and invasive testing for obstructive CAD; and (3) explore the incorporation of a new age, sex, and gene expression score (ASGES) assay in evaluating patients, particularly women, with typical and atypical symptoms of obstructive CAD. The expert roundtable was organized around a series of high-level presentations with discussions moderated by the School's Dean, David B. Nash, MD, MBA.

The following summary report synthesizes the information presented and the ensuing discussion and recommendations, and represents the collective contributions of the expert panelists.

\section{EXPERT PANEL}

George A. Andrews, MD, MBA, CPE, FACP, FACC, FCCP, Corporate Chief of Quality, Health Guidance Organization, Humana, Louisville, KY

Susan K. Bennett, MD, FACC, Consulting Cardiologist, MedStar Health Cardiology Associates, Washington, DC** Christopher Boone, PhD, MSHA, FACHE, CPHIMS, PMP, Vice President, Avalere Health, LLC, Washington, DC

Susan M. Campbell, MSW, Director of Public Policy, WomenHeart, Washington, DC

Christine Carter, PhD, MPH, Vice President of Scientific Affairs, Society for Women's Health Research, Washington, DC** Mindy Gentry, MD, Director, WellStar Cardiovascular Disease Program, WellStar Kennestone Hospital, Marietta, GA**

Phyllis Greenberger, MSW, President and Chief Executive Officer, Society for Women's Health Research, Washington, DC

Katherine M. Harris, PhD, Senior Research Scientist, MedStar Health Research Institute, Hyattsville, MD

Dipti Itchhaporia, MD, FACC, FESC, Director of Disease Management, Robert and Georgia Roth Chair for Excellence in Cardiac Care, Hoag Memorial Hospital Presbyterian, Newport Beach, CA

Carolyn Jacobson, Special Assistant to the President, Coalition of Labor Union Women, Washington, DC

Gay Johnson, Chief Executive Officer, National Association of Nurse Practitioners in Women's Health, Washington, DC

Joseph Ladapo, MD, PhD, Assistant Professor of Medicine, Section on Value and Effectiveness, Department of Population Health, NYU School of Medicine, New York, NY**

Alexandra Lansky, MD, FESC, FACC, Associate Professor, Cardiovascular Medicine and Director, Interventional Cardiovascular Research, Yale University School of Medicine, New Haven, CT**

Saralyn Mark, MD, President, SolaMed Solutions, Washington, DC

Mark Monane, MD, MS, FACP, Chief Medical Officer, CardioDx, Inc, Redwood City, CA**

Lynne Perry-Bottinger, MD, FACC, President and Chief Operating Officer, Interventional Cardiology, PLLC, New Rochelle, NY

Rita F. Redberg, MD, FACC, MSc, Professor and Director, Women's Cardiology Services, University of California, San Francisco, $\mathrm{CA}^{* *}$

Alan Smith, MD, Vice President, Health Services, WellCare Health Plans, Inc., Tampa, FL

\footnotetext{
**Presenter

The authors gratefully acknowledge the members of the panel for their insights, discussion, and contributions to the content of this article. The authors also wish to thank and acknowledge Michelle Ho and David Kwon for their assistance.
} 


\section{Current and Usual Care: Identifying Unmet Needs}

$\mathrm{CAD}$ has become a major public health challenge, affecting $6.4 \%$ of all adults - and $5.1 \%$ of women - in the United States annually. ${ }^{3,9}$ The condition accounts for more than $\$ 195$ billion in direct and indirect medical costs. ${ }^{9}$ With continued increases in the number of ambulatory visits and inpatient hospital admissions for CAD, in addition to associated procedures and diagnostic tests (eg, 1.03 million diagnostic cardiac catheterizations each year), medical costs for CAD are projected to triple-from $\$ 272.5$ billion to $\$ 818.1$ billion (real 2008 dollars) between 2010 and 2030. ${ }^{3}$ Results from multiple studies show a steady increase in the number of diagnostic tests ordered for women with cardiac symptoms suggestive of obstructive CAD and, in particular, a rise in tests that increase the patient's exposure to radiation risks without demonstrable benefit to the individual patient. ${ }^{6,10}$

If in doubt that CAD in women remains a population health concern, consider the following:

- More than half $(51 \%)$ of the US population is female. ${ }^{11}$

- Today, more than 41 million women are older than 55 years of age. ${ }^{11}$

- Postmenopausal women are at greater risk of CAD. ${ }^{12}$

- It is more difficult to diagnose CAD in women than in men. ${ }^{13}$

Heart disease causes more deaths than breast cancer for women in all age groups and, each year, more women than men die of heart disease by a factor of $2-3: 1,{ }^{14}$ with the first "heart attack" resulting in death for half of all women with the condition. Although recent AHA statistics show that some levels of parity are being achieved, a continued gender gap in mortality rates from cardiovascular disease remains a concern for women; specifically, the rate is increasing in the 35-44 year old age group, and in African American women in whom the incidence of MI is higher in all age categories, ${ }^{3}$ and the death rate is $41 \%$ higher than that of white women. ${ }^{15}$

The 2014 AHA Consensus Statement on Noninvasive Testing in Women provides an algorithm for evaluating women with symptoms of obstructive CAD whereby treadmill electrocardiogram (ECG) remains the first-line testing recommendation and nuclear imaging tests are reserved for women with diabetes, abnormal baseline ECG, or inability to exercise. ${ }^{7}$ A meta-analysis of patients undergoing diagnostic procedures revealed that, although the positive predictive value (over and beyond symptoms) of nuclear stress myo- cardial perfusion imaging (MPI) and exercise electrocardiography was $15 \%-20 \%$, the NPV was $60 \%$ (ie, a $60 \%$ chance that the patient does not have disease when the test result is negative). ${ }^{16}$ Noninvasive diagnostic uncertainty has resulted in overutilization of invasive diagnostic catheterization. ${ }^{17}$ Based on their review of 398,978 patients from 663 hospitals in the American College of Cardiology-National Cardiovascular Data Registry, Patel and colleagues reported that $62 \%$ of patients who undergo diagnostic angiography have minimal or no stenosis. ${ }^{18}$ Currently available data suggest that noninvasive tests to evaluate patients for obstructive CAD result in many unnecessary ICA procedures, especially among women, because of:

- Variable site-dependent diagnostic accuracy of noninvasive tests

- High rate of false positive (and false negative) results

- Referral bias ${ }^{19,20}$

The current "gold standard" diagnostic pathway is a progressive journey that often begins with imaging, especially nuclear stress MPI or stress ECHO (echocardiography), followed by ICA in many patients. $^{20}$ As patients proceed through each level of diagnostic testing, they are exposed to additional associated risks (eg, procedural complications, radiation exposure, contrast agent reactions, nephrotoxicity). Better methods are needed to help exclude patients with a low likelihood of obstructive CAD from further cardiac testing, thereby avoiding prolonged and costly workups and allowing for more rapid attention to the noncardiac sources of their symptoms.

\section{Challenges and Barriers to Optimal Cardiovascular Care of Women}

\section{Sex-specific differences in disease presentation}

A study by Hemingway and colleagues (74 studies involving 401,315 people living in 31 countries) revealed that angina is $20 \%$ more prevalent among women than men (pooled random-effects sex ratio of 1.20 [95\% confidence interval 1.28 to 1.52$]$ ) with the incidence in nonwhites exceeding that of whites. ${ }^{21}$ When the data are viewed by country, the prevalence among US women is approximately $40 \%$ higher compared with the rest of the world. One reason for this phenomenon is that women with angina present with a broader range of more subtle symptoms. ${ }^{21}$ Table 1 shows

Table 1. Atypical Presentation of Symptoms-Coronary Artery Disease

Typical in Both Sexes $\quad$ Typical in Women

Pain, pressure, squeezing or stabbing pain in the chest. Milder symptoms (without chest pain).

Pain radiating to neck, shoulder, back, arm, or jaw.

Sudden onset of weakness, shortness of breath, nausea/vomiting, indigestion, fatigue, body aches, overall feeling of illness

Pounding heart or change in rhythm. (without chest pain).

Heartburn, nausea, vomiting, or abdominal pain.

Cold sweats or clammy skin.

Unusual feeling or mild discomfort in the back, chest, arm, neck, or jaw (without chest pain).

Dizziness.

Sources: Kyker et al. Curr Womens Health Rep. 2002;2:115-119, Milner et al. Am J Cardiol. 1999;84:396-399, Kreatsoulas C, Shannon HS, Giacomini M et al. JAMA Intern Med. 2013;173(9):829-833. 
the symptoms of CAD that are typical in both sexes along with symptoms that are frequently reported only in women.

Clinicians faced with the task of risk stratifying patients for CAD generally begin with a risk and symptom assessment such as described by the classic Diamond Forrester Classification scheme, a system based on a patient's history and specific chest pain criteria. ${ }^{22}$ In male patients, this classification has been validated to demonstrate a dramatic linear relationship between clinical risk classification and the presence of CAD; this relationship in female patients is not as robust. ${ }^{23}$ Furthermore, the relationship between age and prevalence of $\mathrm{CAD}$ is linear for men; in women, the onset of the disease is delayed until the perimenopausal age at which the prevalence accelerates until it approximates the prevalence in men. ${ }^{24}$

\section{Differences in biology}

The current strategy for diagnosing CAD focuses on the detection of obstructive atherosclerotic plaque, which is less frequently present in women. ${ }^{13}$ Because of the typical findings of smaller arteries, fewer lesions, and the cardioprotective effects from estrogen in women, the most common tests for diagnosing CAD (ie, exercise electrocardiography, stress testing with imaging) are more likely to produce false positive findings on the initial noninvasive tests and result in low rates of obstructive CAD on subsequent invasive testing (ie, ICA). Shaw and colleagues analyzed results of ICA in a stable patient population by sex and ethnicity and found that the presence of CAD was always lower in the female group. ${ }^{13}$

\section{Difference in benefits and risks}

Studies show that women have more adverse effects and complications related to diagnostic testing and treatment (eg, radiation exposure, contrast agent-induced nephropathy), an increased risk of thyroid dysfunction related to contrast agents, and an increased risk of bleeding and vascular complications following invasive catheterization. ${ }^{25,26}$

Moreover, in the United States, nuclear stress MPI is the dominant source of cumulative radiation from medical sources. ${ }^{27}$ The radiation exposure of a single MPI is equal to that of 40 mammograms. ${ }^{28}$ Also, incidentally discovered abnormalities can lead to additional computerized tomography (CT) scans, biopsies, and surgeries - all of which may result in unnecessary patient anxiety. ${ }^{29}$

\section{Efforts to Improve Care}

\section{Regulatory and policy changes}

Recent regulatory and policy initiatives have substantial implications for women's cardiovascular health in response to evidence of inappropriate use of diagnostics in obstructive CAD. ${ }^{6}$ The Heart Truth Campaign is a concerted effort on the part of the National Institutes of Health/National Heart, Lung, and Blood Institute (NHLBI) to raise awareness of heart disease and risk factors (eg, smoking, hypercholesterolemia, sedentary lifestyle, diabetes, hypertension, obesity) among women ages 40-60 years. Although women continue to be underrepresented in NHLBI-sponsored cardiovascular disease research trials and phase III treatment trials, ${ }^{30}$ progress is being made as the result of targeted initiatives; for instance, the Society for Women's Health Research 2011 10Q Report: Advancing Women's Heart
Health through Improved Research, Diagnosis and Treatment, ${ }^{31}$ with its call to action and guidance for future research. Furthermore, the Affordable Care Act prohibited insurer gender rating (ie, women cannot be charged higher premiums than men), expanded health insurance access, and eliminated cost sharing for many aspects of preventive care. ${ }^{32}$ Research also shows that there is considerable variability in the dose of radiation to which patients are exposed across different types of CT studies, with as much as a 13fold mean variation between the highest and the lowest dose for the same CT study type. ${ }^{33}$ The Food and Drug Administration recognized the need for a radiation quality and safety measure and has tasked the National Quality Forum with its development. ${ }^{10,34}$

\section{Description of a novel ASGES}

The rationale for developing a blood-based test to detect the likelihood of obstructive CAD has been described at length in the algorithm development study, ${ }^{35}$ in which the use of advanced microarray and quantitative real-time polymerase chain reaction technology were leveraged to isolate the genes significantly correlated with obstructive CAD.

The final algorithm was validated in 2 sequential multicenter studies:

1. Personalized Risk Evaluation and Diagnosis in the Coronary Tree (PREDICT). ${ }^{36}$ At 39 medical centers, researchers obtained blood samples from more than 4000 male and female patients who had been referred for ICA. The PREDICT patient population was used for the development of a blood test that incorporates age, sex, and gene expression. The validation cohort included 526 patients and was an independent set of subjects who had been referred for ICA. On the basis of test results, researchers estimated that the frequency of near normal/minimal angiograms in women is $66 \%$ $70 \%$ compared with $40 \%-43 \%$ in men. Moreover, chest pain symptoms were a discriminator of obstructive CAD in men $(P<0.001)$, but not in women. The ASGES was an independent indicator of obstructive CAD in the overall population (odds ratio [OR] 2.53, $P=0.001)$ as well as in the female (OR 3.45, $P=0.001$ ) and the male (OR 1.99, $P=0.001)$ subgroups separately. MPI was not found to be an independent predictor of obstructive CAD in either men or women; only $45 \%$ of men and $22 \%$ of women with positive MPI had obstructive CAD while $35 \%$ of men and $18 \%$ of women with a negative MPI had obstructive CAD.

2. Coronary Obstruction Detection by Molecular Personalized Gene Expression (COMPASS). ${ }^{37}$ At 19 community-based practices, researchers obtained blood samples from 431 male and female patients with symptomatic chest pain (angina or angina equivalents) who had been referred for nuclear stress MPI. The study was limited to patients without known obstructive $\mathrm{CAD}$, prior $\mathrm{MI}$, or prior revascularization procedure. Test results were not reported to the ordering physician. In an evaluation of the comparative effectiveness, ASGES had higher sensitivity ( $89 \%$ versus $27 \%, \quad P<0.001)$ and NPV $(96 \%$ versus $88 \%$, $P<0.001)$ than MPI for ruling out obstructive CAD. 
Once validated, research efforts focused on formally demonstrating the clinical utility of incorporating gene expression information into clinical decisions. Approximately 1000 patients have been studied in subsequent clinical utility-related trials, and those with low ASGES $(\leq 15)$ were unlikely to have been referred for cardiology care or further downstream testing $(<10 \%$ in these studies) and those with elevated scores $(>15)$ were more likely to have further testing ( $>70 \%$ in these studies). The differences in referral rates and downstream testing were statistically significant. Subgroup analyses among women patients also underscored these findings. ${ }^{38,39}$ Importantly, the lower referral rate for additional testing is associated with a low rate of major adverse cardiovascular events during patient follow-up. ${ }^{8}$

A cost analysis revealed that substantially fewer nuclear stress MPI tests (4008 vs. 5200) and ICA tests (1742 vs. 2179) would be performed on patients whose risk of obstructive CAD had previously been assessed by an ASGES test and who had low scores. ${ }^{40}$ This budget impact modeling study concluded that use of the ASGES test could be associated with costs savings of $\$ 0.77$ per member per month.

\section{Panel Discussion and Policy Recommendations}

In general, the chief role of a diagnostic test is to provide accurate, additive information that guides clinical decision making and actions (eg, behavior modification, change in medical management). Ideally, these actions lead to improved health outcomes and a greater degree of clinician and patient reassurance at no significant risk to the patient.

A patient's desire for certainty may influence a clinician to continue testing until the diagnosis is definitive, thereby exposing a substantial percentage of patients to unnecessary procedural complication risks or potential adverse events. The ASGES test scores would be of considerable value to both the patient and the clinician and contribute to informed decision making regarding the need for further testing. ${ }^{8}$

There is growing acceptance of genomic testing, particularly as it relates to cancer risk. ${ }^{40}$ With the growing acceptance of applied genomics or "precision medicine," the timing and environment seem appropriate for the incorporation of a new diagnostic aid for obstructive CAD that incorporates age, sex, and gene expression inputs to help inform the diagnostic and treatment pathway. The evidence base for the ASGES test is promising. ${ }^{41,42}$

In the new environment of health reform, there are incentives for appropriate testing and clinician behavior. For clinicians, the development and implementation of appropriate use criteria for diagnostic testing of CAD will be important steps, as will clinical quality measures with related economic incentives to drive clinician behavior. For payer systems, Accountable Care Organizations and PatientCentered Medical Homes operate in an environment where performance measures matter. There will be added incentives to avoid unnecessary tests as the fee-for-service (ie, volume-based payment) model moves toward a capitated model in which compensation also is driven by value. Finally, panelists report that patient requests for "no needles or dyes" are increasing. Patient engagement in decisions relating to their personal health-an essential element in health reform-requires the formation and maintenance of physician-patient "partnerships." Every time a new tech- nology is introduced, there is a need to educate both physicians and patients about the technology's potential benefits, risks, and limitations.

There was general agreement among the experts on the following points:

1. There is a need for increased awareness of the biologic differences between women and men with respect to cardiovascular disease. Education efforts should focus on physicians, other health care professionals (eg, nurse practitioners and physician assistants involved in primary care and cardiology care), and consumers.

2. For women, the diagnostic evaluation process for obstructive CAD is challenging because of lower pretest probability, atypical symptom presentation, and greater prevalence of microvascular disease. Clinicians should favor rule-out strategies when developing a diagnostic and management plan for these patients (ie, tests with high sensitivity and NPV).

3. For both sexes, utilization of diagnostic testing for $\mathrm{CAD}$ is high and costly. Uncertainty in diagnosis prompts more testing, resulting in health care inefficiencies and increased costs. Better methods and protocols are needed to help clinicians identify patients with a higher likelihood of obstructive CAD who should be referred for advanced cardiac imaging.

4. Advanced cardiac evaluation of women is largely dependent on diagnostic imaging tests that are not optimized for-and hence are less accurate for-women. New, sex-specific diagnostic options should be considered for inclusion in clinical practice guidelines.

5. Potential risks and complications associated with cardiac diagnostic tests (eg, near-term risks such as contrast dye reactions and vascular injury, longer-term complications such as increased cancer risk) should be carefully weighed, especially in women, because of their higher rate of complications.

6. Gene expression evaluation of patients with symptoms of obstructive CAD provides reliable, personalized information by means of a safe test on whole blood samples. Promising data suggest that the ASGES test adds value to clinical diagnosis and patient management decisions by helping avoid unnecessary noninvasive cardiac imaging and ICA procedures and their associated risks and complications. The Corus CAD test is the only sex-specific blood test currently available that accurately excludes obstructive CAD, particularly in women. As such, it should be given serious consideration by clinicians, commercial payer organizations and patients as a means for safe, convenient, and accurate identification of symptomatic disease.

\section{Author Disclosure Statement}

The authors declared the following potential conflicts of interest with respect to the research, authorship, and/or publication of this article: Drs. Skoufalos and Nash, and Ms. Clarke are employed by the Jefferson School of Population (JSPH) of Thomas Jefferson University. JSPH received funding from CardioDX, Inc. for program development, meeting management, manuscript development, and editorial services management. Dr. Ladapo's work is supported 
by a K23 Career Development Award (K23 HL116787) from the National Heart, Lung, and Blood Institute (NHLBI), and he serves as a consultant to CardioDx, Inc. Dr. Ladapo and Dr. Lansky received honoraria for participating in the roundtable. Dr. Monane is an employee and shareholder of CardioDX, Inc., developer of the diagnostic test discussed in this article. CardioDX sponsored the Roundtable and provided financial support for the development of this manuscript.

\section{References}

1. Institute of Medicine. Exploring the Biological Contributions to Human Health: Does Sex Matter? April 24, 2001. http://www.iom.edu/Reports/2001/Exploring-the-BiologicalContributions-to-Human-Health-Does-Sex-Matter.aspx. Accessed September 12, 2014.

2. Bairey Merz CN, Mark S, Boyan BD, et al. Proceedings from the scientific symposium: sex differences in cardiovascular disease and implications for therapies. J Womens Health (Larchmont). 2010;19:1059-1072.

3. Go AS, Mozaffarian D, Roger VL, et al. Heart disease and stroke statistics-2014 update: a report from the American Heart Association. Circulation. 2014;129:e28-e292.

4. Miller CL. A review of symptoms of coronary artery disease in women. J Adv Nursing. 2002;39:17-23.

5. Patel MR, Peterson ED, Dai D, et al. Low diagnostic yield of elective coronary artery angiography. N Engl J Med. 2010;362:886-895

6. Ladapo JA, Blecker S, Douglas PS. Physician decisionmaking and trends in use of cardiac stress testing to diagnose coronary heart disease in the United States, 19932010. Ann Intern Med. 2014;161(7):482-490.

7. Mieres JH, Gulati M, Bairey Merz N, et al. Role of noninvasive testing in the clinical evaluation of women with suspected ischemic heart disease: a consensus statement from the American Heart Association. Circulation. 2014; 130:350-379.

8. Thomas GS, Voros S, McPherson JA, et al. A blood-based gene expression test for obstructive coronary artery disease tested in symptomatic nondiabetic patients referred for myocardial perfusion imaging: the COMPASS study. Circ Cardiovasc Genet. 2013;6:154-162.

9. Centers for Disease Control and Prevention. Prevalence of coronary artery heart disease-United States, 2006-2010. MMWR. 2011;60(40):1377-1381.

10. Fazel R, Gerber TC, Balter S, et al on behalf of the American Health Association Council on Quality of Care and Outcomes Research, Council on Clinical Cardiology, and Council on Cardiovascular Radiology and Intervention. AHA scientific statement approaches to enhancing radiation safety in cardiovascular imaging: a scientific statement from the American Heart Association. Circulation. 2014; 130:1730-1748.

11. U.S. Census Bureau. Table 7. Resident Population by Sex and Age, 1980-2010. www.census.gov/compendia/statab/ 2012/tables/12S0007.pdf. Accessed January 15, 2015.

12. Rubini Gimenez M, Reiter M, Twerenbold R, et al. Sexspecific chest pain characteristics in the early diagnosis of acute myocardial infarction. JAMA Intern Med. 2014;174: 241-249.

13. Shaw LJ, Bugiardini R, Merz CN. Women and ischemic heart disease: evolving knowledge. J Am Coll Cardiol. 2009;54:1561-1575.
14. Bairey Merz CN. Sex, death and the diagnosis gap. Circulation. 2014;130:740-742.

15. American Heart Association and American Stroke Association. Facts. Cardiovascular Disease: Women's No. 1 Health Threat. http://www.heart.org/idc/groups/heart-public/@wcm/ @adv/documents/downloadable/ucm_302256.pdf. Accessed October 1, 2014.

16. Metz LD, Beattie M, Hom R, et al. The prognostic value of normal exercise myocardial perfusion imaging and exercise cardiography: a meta-analysis. J Am Coll Cardiol. 2007,49: 227-237.

17. Lucas FL, DeLorenzo MA, Siewers AE, Wennberg DE. Temporal trends in the utilization of diagnostic testing and treatments for cardiovascular disease in the United States, 1993-2001. Circulation. 2006;113:374-379.

18. Patel MR, Peterson ED, Dai D, et al. Low diagnostic yield of elective coronary angiography. N Engl J Med. 2010;362: 886-895.

19. Kwok Y, Kim C, Grady D, Segal M, Redberg R. Metaanalysis of exercise testing to detect coronary artery disease in women. Am J Cardiol. 1999;83:660-666.

20. Ladapo JA, Blecker S, Elashoff MR, et al. Clinical implications of referral bias in the diagnostic performance of exercise testing for coronary artery disease. J Am Heart Assoc. 2013;2(6):e000505.

21. Hemingway H, Langenberg C, Damant J, Frost C, Pyörälä $\mathrm{K}$, Barrett-Connor E. Prevalence of angina in women versus men: a systematic review and meta-analysis of international variations across 31 countries. Circulation. 2008; 117:1526-1536.

22. Diamond GA, Forrester JS. Analysis of probability as an aid in the clinical diagnosis of coronary-artery disease. $\mathrm{N}$ Engl J Med. 1979;300:1350-1358.

23. Lerner DJ, Kannel WB. Patterns of coronary heart disease morbidity and mortality in the sexes: a 26-year follow-up of the Framingham population. Am Heart J. 1986;111:383.

24. Kannel WB, Castelli WP. The Framingham study of coronary disease in women. Med Times. 1972;100:173-179.

25. Rhee CM, Bhan I, Alexander EK, Brunelli SM. Association between iodinated contrast media exposure and incident hyperthyroidism and hypothyroidism. Arch Intern Med. 2012;172:153-159.

26. Ahmed B, Piper WD, Malenka D, et al. Significantly improved vascular complication among women undergoing percutaneous coronary intervention: a report from the Northern New England Percutaneous Coronary Intervention Registry. Circ Cardiovasc Interv. 2009:2:423-429.

27. Einstein AJ. Effects of radiation exposure from cardiac imaging: how good are the data? J Am Coll Cardiol. 2012; 59:553-565.

28. Berrington de Gonzalez A, Mahesh M, et al. Projected cancer risks from computed tomographic scans performed in the United States in 2007. Arch Intern Med. 2009;169: 2071-2077.

29. Hlatky MA, IriBarren C. The dilemma of incidental findings on cardiac computed tomography. J Am Coll Cardiol. 2009;54:1542-1543.

30. Kim EH, Carrigan TP, Menon V. Enrollment of women in National Heart, Lung and Blood Institute-funded cardiovascular randomized controlled trials fails to meet current federal mandate for inclusion. J Am Coll Cardiol. 2008; 52:672-673.

31. Society for Women's Health Research. 2011 10Q Report: Advancing Women's Heart Health through Improved 
Research, Diagnosis and Treatment. http://swhr-convio.net/ site/PageServer?pagename $=$ policy_10Q. Accessed January $15,2015$.

32. National Women's Law Center. Gender rating in the individual health insurance market. http://hrc.nwlc.org/policyindicators/gender-rating-individual-health-insurance-market. Accessed January 15, 2015.

33. Smith-Bindman R, Lipson J, Marcus R, et al. Radiation dose associated with common computed tomography examinations and the associated lifetime attributable risk of cancer. Arch Intern Med. 2009;169:2078-2086.

34. Keegan J, Miglioretti DL, Gould R, Donnelly LF, Wilson ND, Smith-BIndman R. Radiation dose metrics in CT: assessing dose using the National Quality Forum CT patient safety measure. J Am Coll Radiol. 2014;11:309-315.

35. Elashoff MR, Wingrove JA, Beineke P, et al. Development of a blood-based gene expression algorithm for assessment of obstructive coronary artery disease in non-diabetic patients. BMC Med Gen. 2011;4:26.

36. Lansky A, Elashoff MR, $\mathrm{Ng} \mathrm{V}$, et al. A gender-specific blood-based gene expression score for assessing obstructive coronary artery disease in nondiabetic patients: results of the Personalized Risk Evaluation and Diagnosis in the Coronary Tree (PREDICT) trial. Am Heart J. 2012;164:320-326.

37. Daniels SD, Beineke $\mathrm{P}$, Rhees $\mathrm{B}$, et al. Biological and analytical stability of a peripheral blood gene expression score for obstructive coronary artery disease in the PREDICT and COMPASS studies. J Cardiovasc Transl Res. 2014;7:615-622.

38. Ladapo JA, Sharp D, Maniet B, et al. Use of a personalized medicine, gene expression score influenced decision making around referral to cardiology among female patients presenting to primary care with symptoms suggestive of obstructive coronary artery disease. Medical Decision Making. 2015;35(1):Abstract 8488.

39. Herman L, Froelich J, Kanelos D, et al. Use of a personalized gene expression score in women presenting to primary care with symptoms of suspected obstructive coronary artery disease improves clinical decision making around non-invasive diagnostic testing: gender-specific results from the IMPACT_PCP (investigation of a molecular personalized coronary gene expression test on primary care practice pattern) Trial. Circulation. 2013;128:A18490.

40. Hochheiser LI, Juusola JL, Monane M, Ladapo JA. Economic utility of a blood-based genomic test for the assessment of patients with symptoms suggestive of obstructive coronary artery disease. Popul Health Manag. 2014;17:287-296.

41. Eng C, Hampel H, de la Chapelle A. Genetic testing for cancer predisposition. Ann Rev Med. 2001;52:371-400. Erratum in: Annu Rev Med 2002;53:xi.

42. Vargas J, Lima JAC, Kraus WE, Douglas PS, Rosenberg S. Use of the Corus ${ }^{\circledR}$ CAD Gene Expression Test for assessment of obstructive coronary artery disease likelihood in symptomatic non-diabetic patients. http://currents.plos .org/genomictests/article/use-of-the-corus-cad-gene-expressiontest-for-assessment-of-obstructive-coronary-artery-diseaselikelihood-in-symptomatic-non-diabetic-patients/. Accessed January 14, 2015.

Address correspondence to: Janice L. Clarke, RN Jefferson School of Population Health 901 Walnut Street, $10^{\text {th }}$ Floor Philadelphia, PA 19107

E-mail: janice.clarke@jefferson.edu 